\title{
Glucocorticoid versus immunoglobulin in the treatment of COVID-19-associated fulminant myocarditis
}

\author{
Chia Siang Kow ${ }^{1} \cdot$ Syed Shahzad Hasan ${ }^{2}$ (I)
}

Received: 27 April 2020 / Accepted: 4 May 2020 / Published online: 10 May 2020

(c) Springer-Verlag GmbH Germany, part of Springer Nature 2020

We read with interest the case report on fulminant myocarditis associated with novel Coronavirus disease 2019 (COVID19) by Zeng et al. [1]. The comprehensive discussion on this interesting case is very much appreciated with a description of the treatment plan which included corticosteroid therapy (methylprednisolone) and intravenous immunoglobulin (IVIG). While we acknowledge that corticosteroid and IVIG may be indicated for acute respiratory distress syndrome that was also present in the subject, we would like to discuss their use in the context of fulminant myocarditis.

The efficacy of corticosteroid therapy in myocarditis associated with COVID-19 needs evidence-based discussion. A 2013 Cochrane systematic review [2] on the use of corticosteroids for viral myocarditis with decreased left ventricular ejection fraction included 8 randomized controlled trials with 719 participants. The systematic review reported no significant difference in mortality between corticosteroids and control groups (relative risk: $0.93 ; 95 \%$ confidence interval $0.70-1.24)$. The main concern with regards to the use of corticosteroid therapy in coronavirus diseases is a delay in virus clearance. Recently, Ling et al. [3] reported a significantly longer duration of viral RNA detection in oropharyngeal swabs and feces among COVID-19 patients treated with corticosteroid. In addition, corticosteroid therapy may be one of the underlying causes of significant secondary infections identified in the subject.

On the other hand, the strength of evidence of IVIG is stronger in the treatment of myocarditis compared with corticosteroid therapy. Pooled results from a 2019 metaanalysis [4] of 13 studies with 1534 cases on the efficacy of intravenous immunoglobulin (IVIG) in the treatment of

Syed Shahzad Hasan

s.hasan@hud.ac.uk

1 School of Postgraduate Studies, International Medical University, Kuala Lumpur, Malaysia

2 Department of Pharmacy, University of Huddersfield, Huddersfield, UK acute myocarditis showed that IVIG therapy significantly reduced in-hospital mortality (odds ratio: $0.44,95 \%$ confidence interval 0.17-0.71) and improved the left ventricular ejection fraction (odds ratio: 1.73, 95\% confidence interval 1.34-2.13) in patients with acute myocarditis. Specifically, among patients with acute fulminant myocarditis, IVIG exhibited a significantly higher survival rate (odds ratio: $2.80,95 \%$ confidence interval 1.16-6.77). As suggested by the authors, the damage to the myocardium in fulminant myocarditis may be mediated by immunological mechanisms rather than by the direct effect of COVID-19. IVIG has been shown to decrease cardiac inflammation and downregulate pro-inflammatory cytokines that have direct negative inotropic effects, which explains its benefits in myocarditis [5].

In conclusion, we believe, based on available evidence, that IVIG may be a potentially effective therapy, though large trials may need to confirm its efficacy in COVID-19 patients with myocarditis. The available is not strong enough to support the use of corticosteroid therapy for the treatment of myocarditis associated with COVID-19 as the benefits are uncertain coupled with possible delayed viral clearance and risk of secondary infections.

\section{Compliance with ethical standards}

Conflict of interest None declared.

\section{References}

1. Zeng JH, Liu YX, Yuan J, et al. First case of COVID-19 complicated with fulminant myocarditis: a case report and insights [published online ahead of print, 2020 Apr 10]. Infection. 2020. https://doi.org/10.1007/s15010-020-01424-5.

2. Chen HS, Wang W, Wu SN, Liu JP. Corticosteroids for viral myocarditis. Cochrane Database Syst Rev. 2013. https://doi. org/10.1002/14651858.CD004471.pub3. 
3. Ling $\mathrm{Y}, \mathrm{Xu} \mathrm{SB}$, Lin $\mathrm{YX}$, et al. Persistence and clearance of viral RNA in 2019 novel coronavirus disease rehabilitation patients [published online ahead of print, 2020 Feb 28]. Chin Med J (Engl). 2020. https://doi.org/10.1097/CM9.0000000000000774.

4. Huang X, Sun Y, Su G, Li Y, Shuai X. Intravenous immunoglobulin therapy for acute myocarditis in children and adults. Int Heart J. 2019;60:359-65.

5. Leung DY, Burns JC, Newburger JW, Geha RS. Reversal of lymphocyte activation in vivo in the Kawasaki syndrome by intravenous gammaglobulin. J Clin Invest. 1987;79:468-72. 